\title{
La vivienda "tradicional" en la provincia de Málaga. Aproximación a partir del Inventario de arquitectura popular
}

\section{Pilar Ordóñez Vergara}

A los vecinos que me permitieron entrar en sus casas

El Inventario de arquitectura popular, iniciado en 1993, se estructuró en tres fases, centradas cada una de ellas en los lugares de producción y transformación ( ${ }^{\text {a }}$ fase, 1993-1994), en lugares de habitación ( $2^{\text {a }}$ fase, 1995-1996) y, finalmente, lugares de sociabilidad ( $3^{\mathrm{a}}$ fase, 1996-1997); fases que si no completaban un inventario, sí complementaban el conjunto de categorías y tipos arquitectónicos por inventariar.

En las tres fases participél realizando el trabajo correspondiente a la provincia de Málaga ${ }^{2}$

El Inventario pretendía conocer para proteger, conjugando -al menos de forma implícita desde la segunda fase- dos formas de enfoque: la del estudio y la del inventario propiamente dicho ${ }^{3}$.

Los datos escogidos de entre el universo de hechos, plasmados en la información documental contenida en las fichas y aportada en el material fotográfico, serviría de base a posteriores trabajos analíticos sobre morfología, funcionalidad, terminología, cartografía etnográfica, etc.

En esta fase correspondiente a la vivienda, la provincia se definió como marco amplio de referencia, siendo el marco real de trabajo la comarca, abarcable en términos y tiempo operativos, y el marco básico de referencia el núcleo de población, contextualizado en su comarca.

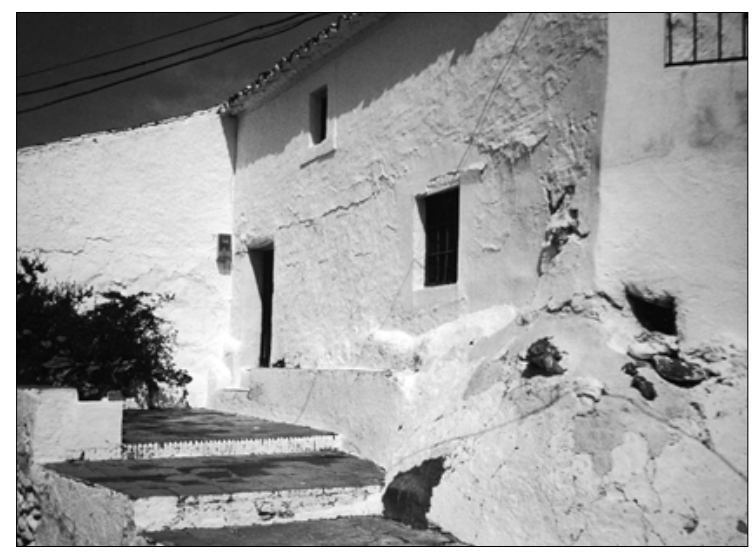

\section{SOBRE OBJETOS, MÉTODOS Y PROCEDIMIENTOS}

El objeto a inventariar, dicho en términos generales, ha sido el inmueble levantado según técnicas y concepción "tradicional", dedicado preferentemente a habitación, ubicado en medio rururbano, en hábitat concentrado, teniendo en cuenta que, tratándose de contextos etnográficos, la interactividad de la actitud vital cotidiana representa con frecuencia la alteración del objeto en función tanto de su adaptación a las necesidades de la actividad o del cambio de la misma, como a las modas o nuevos usos.

Desde el inicio quedaron fijados los criterios principales de trabajo: priorización de la arquitectura vernácula, con aceptable nivel de mantenimiento (mayor o menor integridad); criterio comarcal-geográfico: ámbito local; selección representativa en función de los tipos de vivienda establecidos tras un reconocimiento del pueblo.

La ficha de registro, a partir de una tipología socioeconómica dada, perseguía establecer una tipología constructiva y espacial, así como detectar cambios y variaciones locales o comarcales ligados a tradiciones culturales o a cuestiones geográficas (topográficas, de disponibilidad de material, etc.), compartiendo la afirmación [Rodríguez. Becerra, 1984] de que en Etnografia debe presidir fundamentalmente el criterio de uso común o frecuencia al de excepcionalidad, pero sin olvidar que la presencia de estas "excepciones" a menudo es el resultado de la desaparición del resto de la muestra.

El trabajo en su desarrollo requería una metodología etnográfica y un enfoque transdisciplinar para afrontar distintos niveles de análisis: de aspectos técnico-constructivos, volumétricos y espaciales; de contextos etnográficos; de contextos históricos, no conductuales que perviven en la tradición constructiva y fosilizan en la obra arquitectónica; de análisis espacial territorial y de relación con el entorno.

La mecánica del trabajo se basó en dos estrategias complementarias:

I. información documental y bibliográfica (especialmente monografías, trabajos sistemáticos -inventarios histórico-artísticos- y guías);

2. información de campo, con dos partes bien diferenciadas: 
a) en primer lugar la entrevista, con informantes de cada localidad, guiada con un cuestionario, y

b) el inventario propiamente dicho con la localización de los inmuebles y lugares, la toma de fotografías (del interior y del exterior, encaminada a recoger tanto la generalidad como la particularidad de los objetos, muebles o inmuebles a inventariar-desde la individualización del objeto al reflejo de soluciones técnicas, etc.); y la realización de croquis para la valoración del espacio interior, su organización y distribución; lo que a su vez conlleva una entrevista específica sobre el inmueble y la actividad en él desarrollada.

En este punto hay que resaltar las dificultades que plantea la misma naturaleza del trabajo, en especial el acceso al interior de las viviendas. La forma más práctica ha resultado ser la aproximación a través del Ayuntamiento, y la posterior visita a las casas, acompañada por un empleado municipal o por un vecino. Esta colaboración resulta más fácil en los pueblos de pequeño y mediano tamaño, y más compleja en los de mayor población. El objetivo era disponer de un "introductor" que minimizara la natural desconfianza del propietario o usuario de la vivienda. En otras muchas ocasiones, el acercamiento a la casa se hizo directamente, sin mediación alguna.

\section{EVALUACIÓN}

El trabajo en la provincia de Málaga, dividida en nueve áreas o comarcas, se desarrolló en cuatro comarcas: Altiplanicie de Ronda, Valle del Guadalhorce, Ajarquía, Montes de Málaga; en la primera de ellas en la totalidad de poblaciones y en las tres restantes, sólo parcialmente, habiéndose realizado I 12 fichas correspondientes a 25 localidades, con una media de cuatro fichas por localidad. Según las categorías socioeconómicas previamente establecidas, aproximadamente el $50 \%$ corresponden al tipo vivienda de pequeño propietario/jornalero, un $30 \%$ a vivienda de mediano propietario, un $15 \%$ a gran propietario, un $1 \%$ a vivienda de ganadero $y$, finalmente, un $4 \%$ a vivienda de artesano.

El trabajo realizado permite avanzar resultados en esas cuatro comarcas y plantear problemas a resolver respecto de los tipos arquitectónicos y de la existencia de referentes geográficos en la concreción de los mismos, así como en la revalorización del contexto histórico, advirtiendo que los porcentajes de cada grupo no fueron establecidos a priori desde un estudio al efecto, no estando pues ponderados, por lo que no puede extenderse su interpretación más allá del contexto estricto del trabajo.

\section{CONSIDERACIONES SOBRE SU ESTADO ACTUAL}

El Inventario de Arquitectura Popular (1993-1997) constituye un intento de resolver la cuestión del conocimiento de la entidad de ese patrimonio, de sus ele- mentos, pero la restricción de su alcance a la "individualidad", su planteamiento más propio de "estudio" y la limitación de medios, económicos y de personal, para su realización -condicionando obligatoriamente sus resultados- no pasa de ser una primera aproximación al problema en el camino de dar una respuesta correcta.

La realización de este trabajo pone de manifiesto una gran carencia de protección a escala municipal de este elemento del patrimonio histórico; y en contraste, la despreocupación de algunos Ayuntamientos y el interés de otros en el trabajo que se realiza, en su posible repercusión y en el acceso a esa información. En cualquier caso, cuando iniciativas de demanda de protección del patrimonio inmueble vernáculo han partido de entidades locales, la respuesta ha sido desigual.

\section{Gráfico 1. Distribución de viviendas por tipologías}

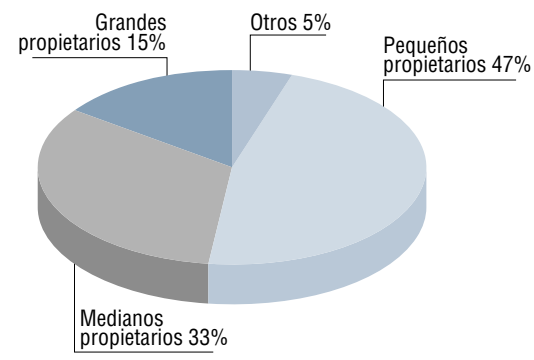

Esto afecta especialmente a las poblaciones medias y pequeñas, en las que la atención urbanística ha sido insuficiente al haber aplicado (cuando se ha hecho, que no en todas) una normativa general de ámbito provincial ajena a consideraciones topográficas, geográficas o históricas, y con atención, si la hay, exclusivamente a las viviendas, pero no a otros elementos integradores del paisaje. No hay en estos casos una respuesta municipal única al problema de la desaparición de la arquitectura vernácula: mientras para algunos es un grave problema (que manifestaban interesándose por el trabajo del Inventario que se estaba realizando, su posible repercusión y el modo de acceso a esa información), en otros la despreocupación es total. En este sentido hay que decir que sólo se conserva aceptablemente en aquellas poblaciones donde los vecinos manifiestan interés por el mismo, ya que la normativa -caso de existir-es ignorada en la mayoría de los casos: los Ayuntamientos tienen, por decirlo de modo simple, la última palabra, pero la relación entre vecinos -y entre familiares- que representa su razón de ser condiciona su actuación. Además, los planes de rehabilitación de la Dirección General de la Vivienda en el medio rural no contemplan en absoluto ${ }^{4}$ el mantenimiento de elementos constructivos o tipologías arquitectónicas tradicionales, al aplicar directamente la normativa V.P.O.

Así, a falta de un interés general por la cuestión, respecto a la conservación y mantenimiento con mayor o menor integridad de la vivienda, la conclusión a la que se llega de forma inmediata es que se mantienen 

Arquitectura Popular. Fase II

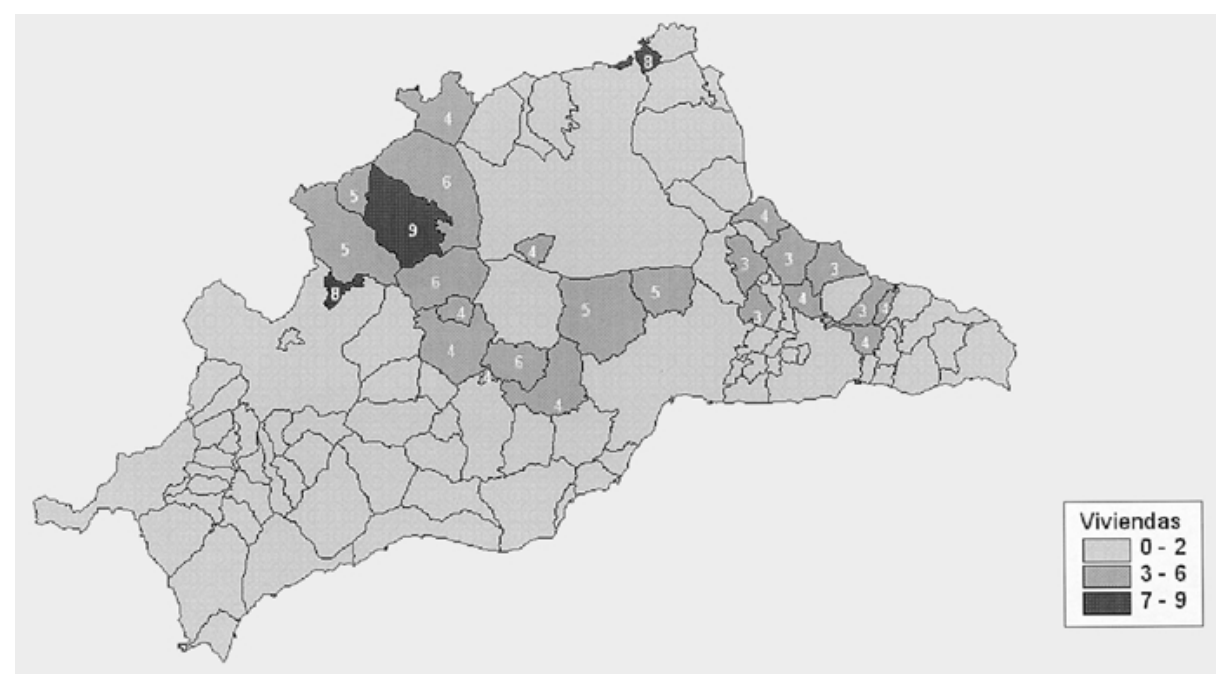

en su integridad aquellos inmuebles que responden a dos situaciones diferentes y opuestas:

- el caso en el que se trata de infraviviendas por la ausencia de condiciones elementales de habitabilidad, con un carácter marginal o cuasimarginal, no transformadas porque sencillamente no se ha podido disponer de recursos para ello5, y

- el caso de viviendas que mantienen simbólicamente un cierto status social, cuidadas y conservadas con orgullo por sus propietarios.

Algunos elementos de arquitectura vernácula habitacional pueden ser tratados, a priori, desde la singularidad, porque así han sido concebidos e interpretados: desde la expresión de un status social, o la manifesta-

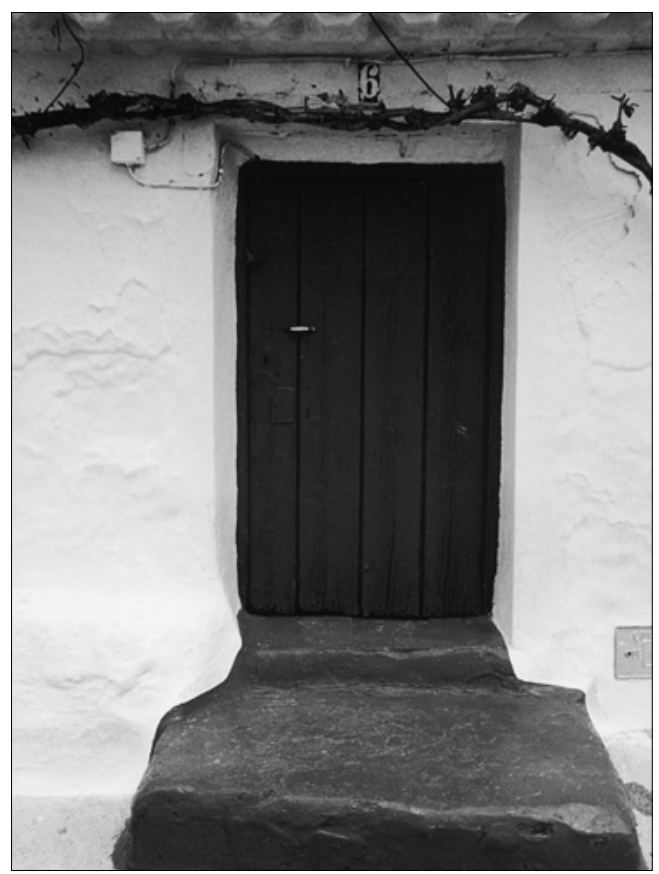

ción de una funcionalidad concreta; pero otros, obligatoriamente, tienen su sentido en el conjunto, especialmente en el caso de la arquitectura más claramente vernácula, la que proviene de la autoconstrucción, pertenenciente a las clases sociales más bajas, no puede desgajarse el conjunto con protecciones individualizadas, dándoles un carácter falso, que ni tienen ni han tenido, esto es, pueden tomarse ciertas viviendas como modelo en cuanto integrantes de un conjunto, pero no como elemento a singularizar. Las viviendas registradas en el Inventario son únicamente una muestra de ese conjunto patrimonial, por lo que únicamente parece pertinente su catalogación en el contexto de la preservación del conjunto.

\section{ALGUNAS CONCLUSIONES Y PROPUESTAS}

El Inventario, del que lo realizado hasta el momento debería considerarse tan sólo un avance y ensayo, debería en su continuidad responder a una problemática social inmediata como es la protección de patrimonio arquitectónico de carácter vernáculo en la Comunidad Autónoma de Andalucía, competencia de la Junta de Andalucía, tal y como se define en el Estatuto de Autonomía; sirviendo, en consecuencia, para el conocimiento del mismo, debiendo estar ideado desde unos presupuestos patrimoniales y científicos rigurosos, y conduciendo a la correcta evaluación de la entidad de ese patrimonio y de los problemas que su conservación plantea.

El objetivo último no debe ser otro que el de servir para la elaboración de una serie de medidas que permitan, con su aplicación, la superviviencia de este tipo de arquitectura, en franco retroceso en las últimas décadas y anecdótica ya en buenas parte de las poblaciones andaluzas, y con ello evitar la pérdida de un aspecto imprescindible de la comunidad como son los elementos que conforman su identidad, como una muestra más de la diversidad cultural universal. 
Gráfico 3.

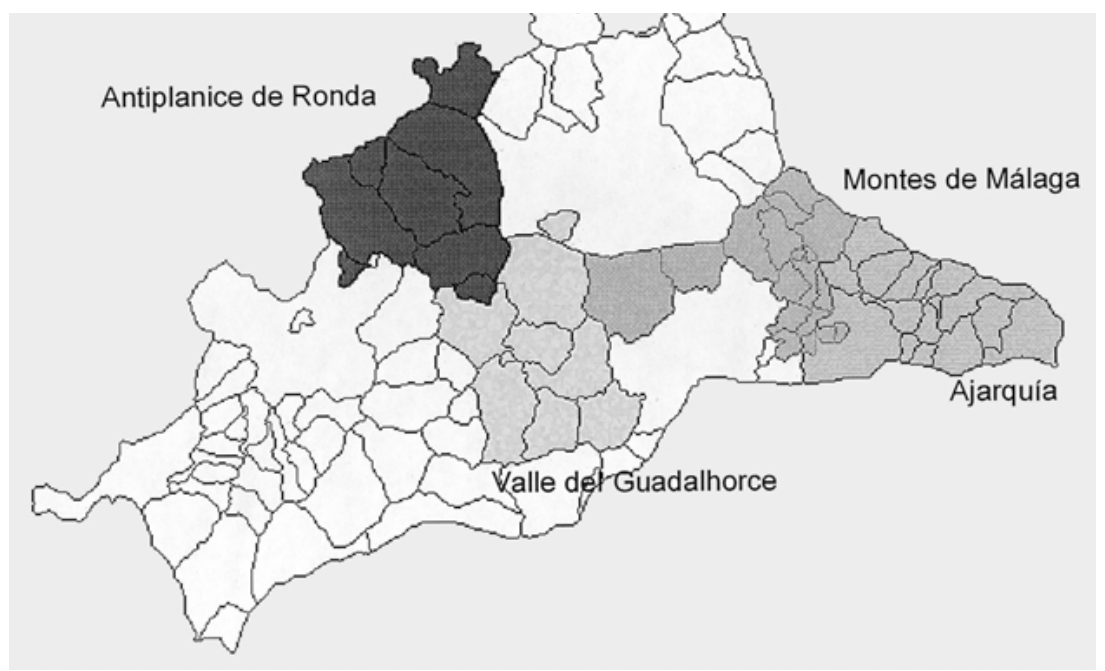

La desvalorización del mundo rural en las últimas décadas dio lugar a un importante abandono, y "desprecio", de los lugares, casas o pueblos en los que se vivía: no había interés en conocer lo propio, no se le veía valor alguno. Desde entonces hasta ahora, se ha producido, pues, una fuerte transformación. El cambio era en muchos casos necesario: había que adecuarse a las necesidades (higiénicas y de todo tipo) de los tiempos que corrían, había que alejarse, siquiera mentalmente, de la penuria y estrecheces de otros tiempos. En ese sentido, se puede señalar que el aumento de viviendas desocupadas en los pueblos es un proceso paralelo al aumento del número de viviendas de nueva planta: se tira la vieja para hacer la nueva. Se debe asumir, por el contrario, la importancia de la arquitectura tradicional en el desarrollo de las pequeñas y medianas poblaciones.

La cuestión principal radica, a mi juicio, en la necesidad de una visión integradora del Patrimonio, basada en soluciones totalizadoras e implicadoras, huyendo de otras parciales o de compromiso. Es necesario afrontar la realidad de ese patrimonio y buscar soluciones para el mismo en su propio contexto y en un tiempo razonable, en sus manifestaciones: inmuebles, muebles y actividades.

Los inmuebles deberían estar protegidos desde la normativa urbanística y la ordenación territorial, teniendo en cuenta la diversidad de su naturaleza. Un cambio en el enfoque de la cuestión, asumiendo la protección de estos elementos patrimoniales como objetivo prioritario, al tener fuertes implicaciones en el desarrollo de Andalucía y al tratarse de un patrimonio vivo, tan vulnerable, de recuperación imposible por el falseamiento que esta supondría, ajena a su propia naturaleza. La orientación hacia el marco territorial implicaría una apuesta presupuestaria y de planteamiento sólida, que podría aportar soluciones desde una perspectiva global, en plazos de tiempo justos. Las experiencias aisladas de protección sin tener en cuenta a quienes los habitan y a quienes les destruyen no han dado el resultado que presumiblemente cabría esperar.
Así, si el objetivo es conocer, catalogar y proteger esos elementos patrimoniales, habría que trabajar en el contexto de Catálogos de Patrimonio, que deberían ser el resultado de un registro exhaustivo y sistemático de los elementos pertinentes, para el que se partiría de la valiosa experiencia del Inventario de Arquitectura Popular realizado hasta ahora, pero con un planteamiento bien diferente:

- Basado en el trabajo de grupos provinciales (sin desdeñar la importancia de un criterio geográfico, por cuanto éste proporciona conocimiento más profundo, homogéneo y multiperspectívico del territorio) integrando diferentes planteamientos disciplinarios.

- Integrado, y en colaboración, con otros organismos implicados en el tema, estatales, autonómicos y provinciales -Consejería de Obras Públicas, Diputaciones Provinciales (Servicios de Arquitectura y Ordenación del Territorio), Ayuntamientos, Centros y Consorcios de Desarrollo Rural, etc.

- Dotado suficientemente de recursos humanos y económicos, con una programación real temporal y presupuestaria.

- Que tenga en cuenta no sólo los aspectos más directamente ligados a la cuestión "monumental", legal o técnica, sino también la necesidad de incluir un análisis especializado sobre la repercusión sociológica y económica de la transformación - destrucción en tantos casos- del hábitat tradicional, de su conservación y mantenimiento.

\section{SELECCIÓN DE DATOS}

En las monografías y trabajos genéricos sobre arquitectura tradicional en la provincia de Málaga se distingue normalmente en tres tipos, atendiendo a las características geográficas y topográficas, como son: 
costero, de sierra, y de vega. Esta estructuración parece, a priori, demasiado simple. Con lo visto hasta ahora, las diferencias entre unas zonas y otras aparecen más patentes a la hora de construir, esto es, en el empleo de materiales y técnicas constructivas, y sobre todo en función de la clase social; pero no lo son tanto en lo que respecta a la concepción de la casa, a la distribución de funciones en su interior, a la variación en dependencias: la casa es, ante todo, un producto histórico, y son muchos más factores los que entran en juego en su concepción que los puramente geográficos, aunque, naturalmente, la topografía, por ejemplo, suponga también un condicionante.

El texto que sigue corresponde en su mayor parte a las memorias parciales del Inventario y constituye por tanto una primera sistematización de la información del trabajo de campo.

\section{Altiplanicie de Ronda}

En general, no suele haber cimentación: la casa se apoya directamente en la roca del suelo, erriza. Cuando era necesario se hacía, de aproximadamente un metro de profundidad.

Sobre tecnología constructiva, hay que señalar que la técnica empleada es adintelada, de soportes de fuerzas perpendiculares. Las impresiones de arco que pueden verse en algunos lugares son tan sólo molduras con valor decorativo.

Los muros de carga son generalmente de mampostería, trabada con barro o seca. En algunas localidades, pero excepcionalmente, son también de sillares. Más común es el empleo de la piedra seca, sin mortero, generalmente sólo hasta una cierta altura, a partir de la que se continúa en mampostería; en esos casos el ancho de los muros, en el caso de Teba, según nos indicaba el informante, el ancho del muro no era mayor de $40 \mathrm{~cm}$. porque las piedras de aquí son chicas y no dan para cruzar. Hay que disponer cada tanto piedras a lo ancho del muro, del exterior al interior para que traben. Al día se alzaba un bancal (un metro aprox.), trabajando un maestro con un peón y otro peón arrimando piedras o tierra, con un cubo o con una tabla -transportada sobre la cabeza.

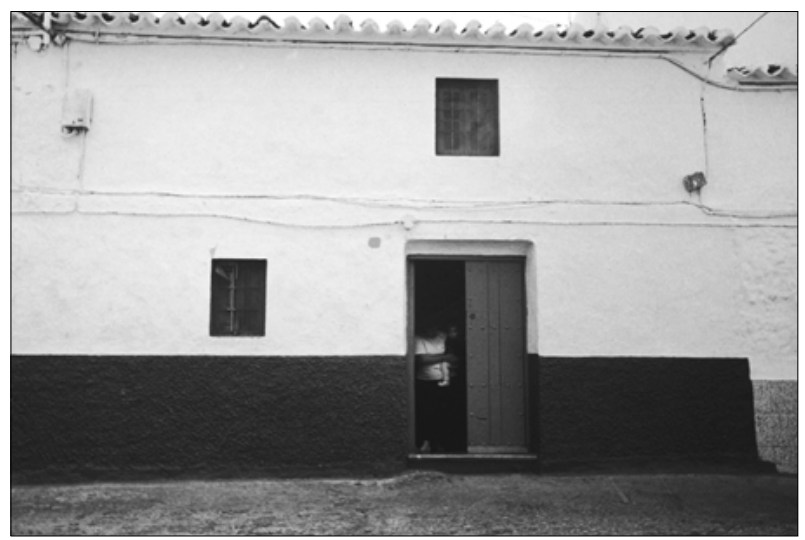

Es muy común el uso del tapial, del barro, para el alzado de los muros, muy pobre en cal pero abundante en mampuestos, en piedras que le dan consistencia. Los cajones eran de cuarenta a ochenta centímetros de espesor, y se compactaban con pisones.

La tabicación en el interior de la vivienda es de ladrillo, de tosca -piedra caliza muy porosa- y cañizo recubierto de yeso.

Por otro lado, en cuanto a la cubierta, entre los albañiles no se emplea el término armadura, sino tejado y tijera, que se compone de planchas -las hileras que descansan sobre el muro, paralelas a éste-, caballete -la viga cumbrera- y vigas -los pare. Éstos últimos van estribados en una plancha sobre el muro de carga, o bien sujetos al muro con una cruceta. Si la crujía es muy ancha, se refuerzan los pares con quitacimbras, tirantas y jabalcón, travesaños a los pares que tienen por objeto evitar la comba de las vigas del tejado. Por encima de las vigas se dispone una cubierta de madera, de tablas cubriendo completamente la superficie. Encima de las tablas se colocan las tejas. En ocasiones la tabla es sustituida por una estructura cañizo, con idéntica función.

El alero es muy sencillo, normalmente un simple listel de ladrillo a tizón. Tan sólo en un caso he apreciado bocateja. En los últimos años se está introduciendo el pico de gorrión.

En cuanto a los forjados, son de vigas tendidas a lo ancho de la crujía sobre las que se coloca cañizo o tablas.

Entre las maderas empleadas, están preferentemente la de pino, de álamo, y, más recientemente, de eucalipto. Las vigas son siempre rollizos, troncos o, por lo general ramas, desbastadas. En casas de sectores más altos en la escala social se emplean cuartones, vigas de sección rectangular.

La fachada, se compone básicamente de una entrada y dos vanos, uno en planta baja y otro en planta alta. En función del status social el número de vanos en fachada se multiplica seriándose simétricamente, tanto en planta baja como en alta: dos ventanas franqueando la puerta, otras dos en la planta superior sobre las ventanas de abajo, etc.

Las ventanas, por lo general, no tienen rejas, y si la tienen suele ser en la planta baja. Una puerta, principal y frecuentemente única, de dos hojas, da acceso a la casa. A veces, hay también una puerta trasera.

En el interior, se suele decorar el arco de transición entre habitaciones con una moldura en el dintel. No se cerraba más que con una cortina, aunque normalmente el dormitorio sí tenía puerta. Con posterioridad se han colocado puertas entre las habitaciones, puertas que no faltaban en las casas de mayor status social. Es chocante como en muchas casas ${ }^{6}$ la cocina se separa del cuerpo casa con una puerta con cerrojo - que se cierra desde el cuerpo casa-, aún habiendo otra puerta con cerrojo entre la cocina y el patio -que se cierra desde la cocina. 
En lo que se refiere al acabado, tanto el exterior como el interior están enlucidos y, normalmente encalados, aunque es muy frecuente el uso de colores en contraste, especialmente en zócalos y en el interior (veras). Se emplean preferentemente verde, rojo, azul, ocre y marrón, contrastándolos con blanco.

En cuanto al espacio interior, hay que decir que la casa elemental es de dos crujías, de dos cuerpos, y como dependencias mínimas tiene, en la planta baja, el cuerpo casa y el cuarto (el dormitorio), y la cámara. La estructura básica es:

(portal, zaguán, sanjuán) - cuerpo casa, casa - comedor, comedorcito - cuarto - patio- corral,

prolongándose en la calle, en la puerta de la casa como espacio de descanso, de charla con los vecinos.

La casa en torno a un patio es privativa de clases media-alta y alta.

La parcela larga en la que se sitúa la casa tiene su expresión en la topografía del terreno y en el hecho de que cada crujía se escalone adaptándose al terreno. En primer término se localiza el espacio habitacional, y en último las funciones relacionadas con la actividad económi$\mathrm{ca}$, normalmente primaria, ya que el lugar para guardar tanto los animales como la producción ha estado en la casa. No siempre el corral o la cuadra tienen entrada trasera: si no puede accederse al mismo por una puerta trasera, se accede por la única puerta de la casa, atravesando los animales la totalidad de la vivienda, marcando el tránsito una banda de empedrado o de cascajo.

Los cuartos, el cuerpo de la casa, el comedorcito y la cocina, si existe, son los espacios realmente domésticos, de acceso sólo para el grupo doméstico y sus más directos allegados. En este caso, la parte social es el portal, la puerta de la calle.

Normalmente, toda la parte habitacional está en la planta baja, incluyendo las habitaciones para dormir. Ahora bien, si se desarrollan actividades comerciales o profesionales en la casa, éstas se localizan en la primera crujía, pasando los dormitorios a la planta alta. El dormitorio principal está, normalmente, a la derecha según se entra en la casa, y tiene una (y a veces única) ventana a la calle (lo que podría poner en relevancia, por un lado, el papel social del matrimonio, por otro una cierta función de vigilancia de la entrada a la casa). Es también espacio de sexualidad socialmente reconocida (a través del matrimonio), de nacimiento y de muerte (el duelo, en el portal y en el cuerpo de casa). El otro cuarto es para los hijos que residen en la casa, esto es, que no están en edad de casarse.

La chimenea en el interior de la casa se relaciona, en lo visto hasta ahora, más con el espacio disponible en el interior de la casa que con la altitud: por ejemplo, en Teba, en las casas de solo dos crujías, con un espacio muy restringido, y en las que no hay una habitación donde tengan lugar las funciones de cocina, la chimenea se sitúa en el cuerpo de casa, y allí, sobre la

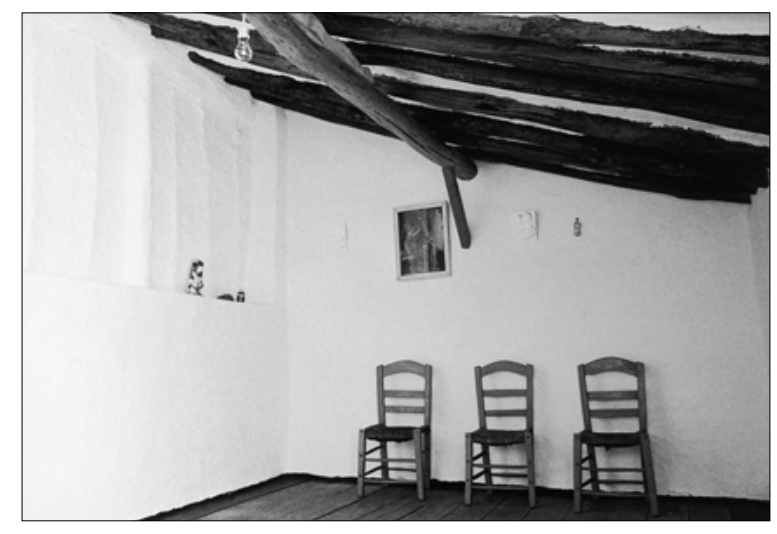

trébede, se cocinaba. Tenía, también, la posibilidad de servir de fuente de calefacción. Pero normalmente la calefacción de la casa se ha realizado (y se realiza) con braseros de carbón: la leña tiene dueño, y el aprovisionamiento no es libre.

El lugar habitual para encontrar la chimenea es pues la cocina: si hay una habitación destinada a ser el lugar donde se prepara la comida, allí está la chimenea. Si no existe esta habitación, allí donde esté la chimenea se localizará la cocina como espacio para la alimentación, con alacenas hornillos y chimeneas. La cocina, como dependencia específica no existe más que en las casas de un cierto status social; aunque en las casas de mediano propietario existe una cocina de la matanza o cocineta, donde se enciende la lumbre de la que sacar brasas para aviar la comida en un hornillo o en un anafre, o para el brasero, y está situada al fondo del patio -que queda así convertido en patio interior.

Igualmente, el cuarto de baño es una dependencia con un fuerte carácter social: en las casas de clase acomodada, desde principios del siglo XX lo había -anteriormente había un retrete, pero no asociado en el espacio con una bañera-, distintas necesidades se asocian con diferentes muebles y dependencias -palanganero, barreño, corral, retrete (fijo o portátil).

La parte alta de la casa, la cámara, se destina a lugar de almacenamiento de la producción para autoconsumo.

Como observación general, el espacio habitado, doméstico, es inferior al espacio total disponible, de producción económica. Los patios y corrales ocupan la mayor parte de la superficie. La casa traza también el eje entre el corral y la calle; por lo general no hay más acceso que la puerta de la fachada, siendo rara una puerta del corral a la calle, una puerta trasera. Igualmente, a la cámara (o camarilla perdía, camarote o granero) se sube desde la casa, salvo en un caso en el que el acceso se realiza desde el corral. La escalera es de uno o dos tramos, y el hueco se utiliza para colocar la despensa. La chimenea es un elemento casi habitual en la vivienda.

Los materiales de construcción son la tierra, (en ladrillo de barro para pavimento y tabicación -ladrillo moruno, dormido, rayona y tochana- y en barro para tapias y paredes de barro); la piedra (mampuestos de caliza, a 
veces también de otras piedras, como toba, caliza porosa y más ligera, tosca, piedra abata o nerisca; transformada en yeso -para enlucidos y acabados-, y cal -que puede emplearse en todo el proceso, desde mezclada con la tierra del tapial para darle más consistencia, hasta el encalado de las paredes, tanto interior como exterior); y materias vegetales como son madera (como material constructivo -pies derechos y vigas en rollizos y cuartones; como elemento de cierre en puertas y ventanas; siendo normalmente de pino y de álamo, y en ocasiones de eucalipto) y caña (para techos y cubiertas; en ocasiones también para tabicación interior, recubriendo un entramado de cañas con yeso).

En general, y válido para las otras tres comarcas, la casa está habitada por una familia nuclear neolocal, que ocupa su propia vivienda. Suele ser propiedad del hombre, del marido: si se pregunta a las mujeres, generalmente responden que la casa era de sus suegros. El ajuar de la casa -el dormitorio y el comedor-es aportado por la mujer.

Aparte de la compra, el sistema de transmisión de la vivienda es el hereditario. Los bienes y propiedades de los padres se reparten de forma igualitaria entre los hijos. Existe una excepción en el caso de que uno de los hijos se haga cargo de los padres hasta la muerte de estos: es "la mejora". De modo que la casa se hacen tantas partes como herederos haya. Si la casa es de grandes dimensiones y todos los hijos están interesados en ella, se divide físicamente en esas partes. Sino, quedan como parte de tasación, de modo que el heredero más interesado en quedarse con la vivienda resarce a los demás del valor de su parte. Es interesante ver como las fachadas traslucen, con la partición y duplicación de la puerta o con las reformas que se manifiestan sólo en un lado de las fachadas el reparto hereditario de la casa. Esa división de la casa puede hacerse también en vertical, de modo que las distintas plantas de la misma pueden corresponder a diferentes viviendas. En el caso de precariedad económica, se llega a dividir la casa a veces en partes mínimas, a las que luego, por compra o por herencia, se van añadiendo otros espacios pertenecientes a los inmuebles contiguos -en horizontal y en vertical-, no teniendo por qué corresponder la vivienda con el límite del espacio construido originalmente. A veces este proceso de decisión de negociación en la valoración de la casa y en el pago a los demás hermanos motiva el que durante largo tiempo la casa esté deshabitada, ocupada ocasionalmente en vacaciones, y con ello se deteriore. En algún caso, debido a lo pequeño de la propiedad, según los informantes, la propiedad -casa o tierras- se distribuía en lotes, con elementos de compensación o mejora, o bien se sorteaban con papeletas, tantas como interesados y lotes.

\section{Valle del Guadalhorce}

Con frecuencia la casa tiene una cimentación mínima, apoyando directamente sobre la roca madre.

Es de interés la técnica constructiva basada en el empleo de bóvedas de cañón -principalmente- o de arista en la planta baja de los inmuebles de cierta entidad, técnica esta ampliamente difundida en la zona, siendo muchos los ejemplos de su empleo.

La técnica muraria habitual es el tapial -con muchas y gruesas piedras-y la mampostería. En la tabicación se emplean tabiques de ladrillo y de caña (estos últimos principalmente para compartimentar las cámaras).

Las cubiertas son de tijera, armadura de parhilera, con cañizo, yeso y tejas. A propósito de la cubierta, en el caso de Casarabonela, Feduchi ${ }^{7}$ la describe de la siguiente manera "cubierta a dos aguas, chimenea de gran porte y remate muy repetido en esta zona. La cubierta de teja, está encalada en aleros, caballete y dos hileras sí, tres o cuatro no". Lo más frecuente es que sólo se pinte el caballete y el borde.

Los aleros son comúnmente de listel. La presencia de pico de gorrión en el caso de Pizarra, donde es relativamente abundante, se da en el entorno de la iglesia, adornada de este modo.

La solería tradicional de ladrillo colorao está siendo sustituida por solería de terrazo. Igualmente están desapareciendo los techos de cuartones y vigas con cañizo -encalado-, que van siendo sustituidos por techos rasos.

Respecto a los vanos, se cierran con elementos de dos hojas; tienen grandes dimensiones en la parte "burguesa" del pueblo, con balcones y cierros. Se adornan también con portadas de ladrillo. De una hoja en el resto de las viviendas: en la casa "mediana", los portales están abiertos, es la puerta de la casa la que se cierra; en la casa "pequeña", en la que no hay portal, la puerta de la casa está abierta o encajada, "cerrándose" con una cortina. Las rejas en las ventanas son habituales en aquellas viviendas de clase social media-alta, habiéndose generalizado en las de clase baja en los últimos años. La rejería de ventanas, en planta baja y alta, y balcones es variada y sencilla. En las casas más modestas no suele haber rejas.

Los acabados de fachada son en blanco de cal -a veces mezclado con otros tintes hasta obtener tonos azules o pajizos-, con zócalo en rojo, marrón, gris, o ladrillo visto; recientemente se ha introducido falsa mampostería.

En el interior, son comunes los acabados en blanco, sin perjuicio de otros, empleados especialmente en los techos: azul, verde, amarillo; en las casas de alto poder adquisitivo abundaba el estucado.

La casa, en términos generales, es de una o dos crujías paralelas a la calle, sobre una parcela rectangular alargada, siendo el lado más corto el de fachada, y adosadas a medianería. La altura de la vivienda tradicional es por lo general de dos a tres plantas (PB+I ó $\mathrm{PB}+2)$, con cubierta a dos aguas. En la vivienda de reciente construcción, o en la antigua reformada son frecuentes las terrazas como cierre de la vivienda, que llegan a veces a cuatro plantas $(\mathrm{PB}+3)$.

De las viviendas vistas, podemos hacer varios tipos que permitan hacer una tipología provisional, a falta de 
completar la comarca. Esta tipología ha sido también la base para seleccionar las viviendas-tipo a inventariar.

Producto de una sociedad agrícola, tan marcadamente diferenciada por la tenencia o no de tierra, que hasta la crisis agraria de las últimas décadas ha venido habitando el pueblo, los tipos de casa van a corresponder a disponibilidad de superficie, al uso de determinados materiales y a la traducción, en el caso de las viviendas del sector social más poderoso, de esta riqueza a la especificidad funcional de las dependencias -con el consiguiente aumento de superficie de la vivienda-y su traducción en elementos simbólicos en la fachada, con portadas y otros adornos.

Un primer tipo es el de vivienda "elemental", la que reúne los elementos imprescindibles para ser denominada tal. Aunque es un tipo ampliamente representado en todas las localidades, no es el predominante. En cualquier caso, la posibilidad de mantenimiento de tradiciones constructivas hace difícil su datación. Consiste en una vivienda de una o dos crujías, con una sola habitación en cada una de ellas, con puerta de doble hoja de acceso -con muchísima frecuencia único-, el mismo para las personas que para los animales. Sin pasillo, las dependencias sirven de paso unas a otras. Una chimenea (humero) en una de las paredes de la habitación principal, localiza el espacio de cocina, aunque en muchas de las viviendas de este tipo la cocina haya sido añadida sobre el espacio de la antigua cuadra, ahora fuera de uso. En la planta alta, a la que se accede por una escalera de obra de un solo tramo, se encuentra la cámara, espacio con valor habitacional o productivo, según las necesidades del momento. Esta casa puede ser también resultado de la partición de una vivienda del tipo que se menciona a continuación.

El tipo de vivienda mayoritario es básicamente el anterior con mayor longitud y anchura de crujías, lo que permite disponer más dependencias en cada una de ellas, y con ello especializar los espacios. La existencia de una tercera crujía no cambia substancialmente el esquema. Así, aparece el portal como elemento de introducción y transición, y el cuerpo de casa como nexo de las diferentes dependencias, tanto en la planta baja como con las de la planta alta.

Un último tipo se refiere a la vivienda de carácter "señorial", una vivienda en la que la que el número de crujías llega a cuatro, y donde por efecto de iluminación interior así como para dotar de valor representativo a la vivienda se introduce un patio interior. Aquí se pasa normalmente a dos o tres plantas, siendo la segunda de habitación, trasladándose las dependencias productivas al patio.

Un tipo nuevo, que aparece a principios de siglo, mantiene básicamente el esquema anterior aunque aumentando el número de dependencias: a partir de las dos crujías principales, un patio centraliza el espacio junto al que se disponen dos crujías, adoptando la planta forma de $U$, cerrado con una reja del resto del patio y del corral. En la segunda planta, sobre el mismo área que en la planta baja se disponen las habita-
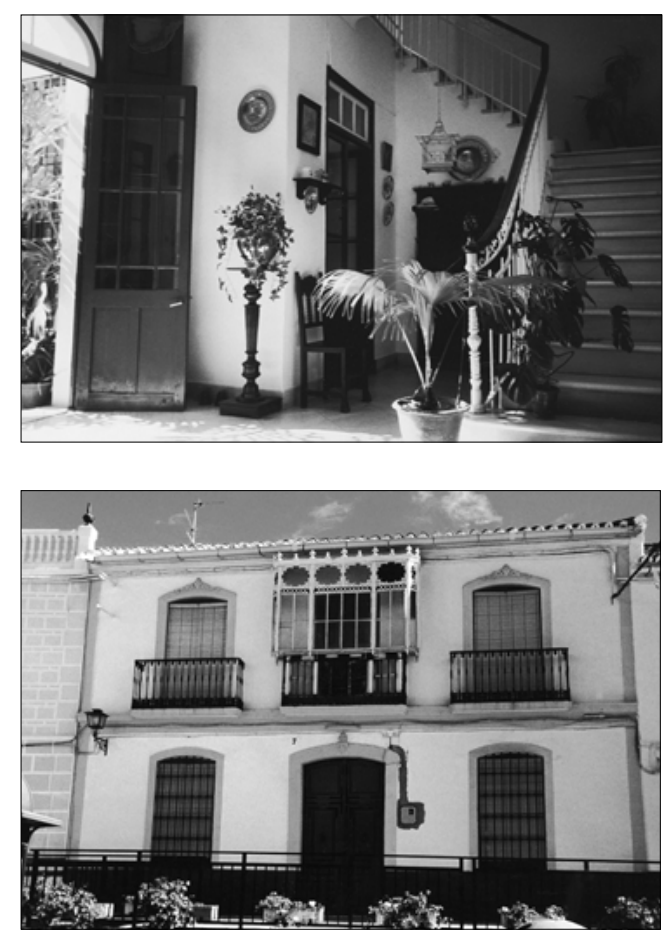

ciones, mientras que las cámaras y pajares se sitúan sobre las zonas productivas de la planta baja, de modo que el espacio productivo y el habitacional se dividen también en vertical.

Tan sólo en un caso se ha constatado la existencia de vivienda con patio central en torno al cual se organiza el espacio -Casarabonela.

La vivienda, en cualquiera de los casos, suele organizarse en un primer espacio de habitación con un carácter doméstico y también representativo. En las viviendas sencillas se trata únicamente del cuerpo de casa -no siempre la casa tiene portal-, habitación que sirve de paso, de distribuidor al resto de la vivienda, y que supone en cierto modo un "escaparate de la casa", al estar la puerta de la calle, principal fuente de iluminación de la vivienda, abierta una gran parte de día. Una chimenea en el cuerpo de casa, con dos alacenas a cada lado, era el espacio para cocinar. Junto a esa habitación se ubica con frecuencia otra de menores dimensiones destinada a dormitorio principal, con finalidad ahora de salita de estar o comedor. La casa en su planta baja continúa con la cuadra y el corral; la cocina, como espacio unifuncional, y el cuarto de baño, se han establecido en los últimos años sobre aquellas dos dependencias. En la planta de arriba se distribuyen el espacio para dormitorio y para granero/trastero/almacén.

En las casas de mayor poder adquisitivo, hay otras dependencias que suponen la especialización y duplicación de algunas de las anteriores, para adaptarlas a una actividad profesional o como elemento de ostentación. Así, el despacho, el comedor y el comedor de diario, y el dormitorio de verano.

La cámara servía principalmente de cascarero para secar las cáscaras de naranja amarga, vendidas ya secas a 

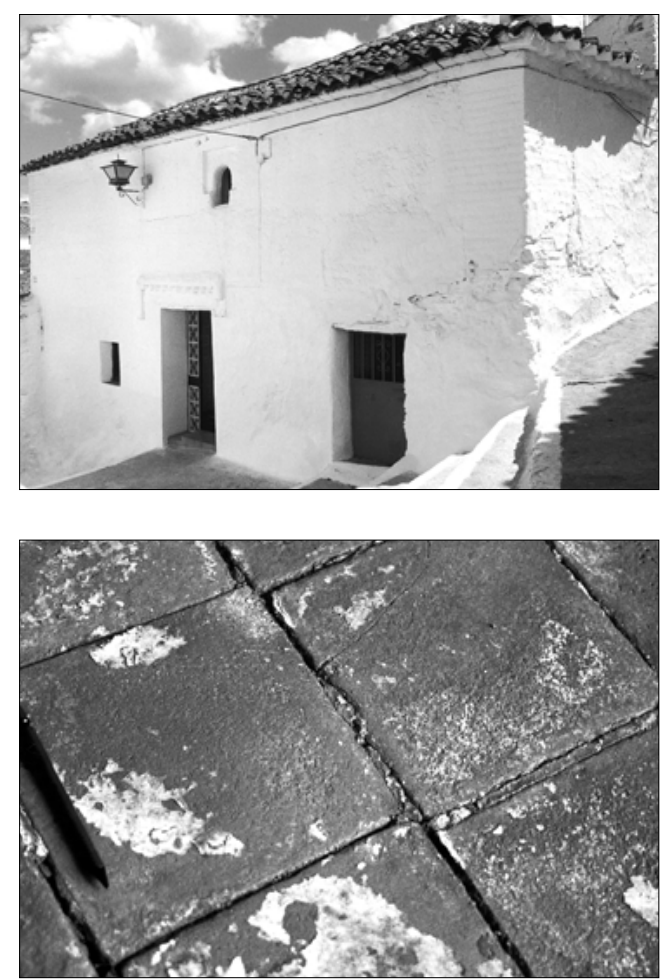

los negociantes levantinos que todas las temporadas llegaban a esta zona comprando las cáscaras de los cítricos para emplearlas como materia prima en la fabricación de pólvora para fuegos artificiales. Con el tiempo y el abandono de la actividad agrícola, la cámara ha sido acondicionada para servir de dormitorio. Se accede a esa dependencia desde el interior de la casa, salvo casos raros en los que el acceso se realiza desde el corral.

El corral o el patio, que antes servía para guardar los animales, ahora se usa como extensión de la casa en verano, como trastero, y en aquellas casas situadas en calles con acceso para coches, en cochera. Su espacio se ha visto además reducido por la extensión de la cocina y la ubicación del cuarto de baño.

Por lo general no hay más acceso que la puerta de la fachada, siendo rara una puerta del corral a la calle, una puerta trasera. En Casarabonela sí suele haber acceso al corral desde la calle, a través de un postigo.

En algunas viviendas de El Valle de Abdalajís se puede ver una ilustración religiosa enmarcada, que, según las vecinas, corresponde a san Pascual Bailón o, según otras, a san Onofre. La primera atribución no corresponde con la iconografía, que, efectivamente, es la de san Onofre ${ }^{8}$. Este santo eremita ${ }^{9}$, cuyo nombre de procedencia egipcia significa el que abre lo bueno, vivía, según las hagiografías ${ }^{10}$, en el desierto, en la más absoluta pobreza, cubriéndose el cuerpo con una piel de animal o con sus propios cabellos, y siendo alimentado por los ángeles que le traían agua y alimentos. Así, según las vecinas, del cuadrito, o de la imagen si era el caso, se colgaba una rosquilla de pan y un tarrito con agua. De este modo, san Onofre puede aparecer como patrón de la indigencia "'. La ubicación del cuadrito en la casa ha cambiado según las informantes: en otro tiempo, en lugar de estar en una pared de la cocina, del cuarto principal como ahora, estaba colocado detrás de la puerta de la calle, en ocasiones junto a alguna herradura -amuleto de la suerte- colgada también de la puerta.

Cuando se inaugura una casa, lo primero que entra es el agua, el vinagre y la sal. También existía la costumbre de enterrar, en las casas con elevado poder adquisitivo, una moneda en los cimientos de los muros maestros. En algunas localidades es tradicional abrir las ventanas y puertas de la casa al paso de la procesión de la Virgen del lugar.

\section{Ajarquía}

En lo que respecta a la cimentación del edificio, en la zona se suele encontrar con frecuencia una capa de pizarra muy cercana a la superficie. A veces incluso se aprovecha para construir sobre ella el muro, rodeando alguna roca -o tajo- que sobresale del suelo. En los casos en los que la pizarra no está muy próxima se ahonda hasta que se encuentra una capa más fuerte.

Además de la mampostería -con o sin mortero, de ladrillo y de piedra seca-, es habitual la fábrica de tapial, terrizo, en muros maestros, que puede ser: de tierra, muy rica en materia orgánica - de color muy oscuro-; con ladrillo, con piedras -en especial de refuerzo en las esquinas-. El empleo de adobe es raro en la construcción de viviendas, aunque resulta habitual en la fabricación de otros elementos anejos, como hornos.

En cuanto a la construcción en tapial, los muros maestros se levantaban con un grosor medio de unos 70 cms, llegándose a alcanzar en algunos casos cerca de Im. Cuando las crujías eran muy anchas, se construían pilares centrales. Vanos -adintelados o de medio punto- comunican las distintas crujías y dependencias.

Respecto a las edificaciones en mampostería, los muros se construían con un grosor algo inferior que en el caso del tapial, alrededor de unos $50 \mathrm{cms}$. El mortero podía ser sólo de barro o de barro con cal y arena (en proporción 3/I). Se colocaba una capa de unos $10 \mathrm{cms}$ de barro y se iban trabando las piedras. Cuando se construía solo con cemento, se preparaba una masa de unos $200 \mathrm{~kg}$. y se humedecía con agua, batiéndose con un rodillo. Cuando se usaba la cal para la mezcla, se echaba una parte de cal por cada tres de arena. Todo ello dependía del presupuesto para la construcción de la vivienda. En muchos casos se emplean varias técnicas en el alzado completo del inmueble: por ejemplo, planta baja construida en mampostería y alta en tapial o bien de ladrillo. Son frecuentes los inmuebles en los que se ha reformado la armadura y la cubierta, elevándolas, usando para ello mampostería sobre el tapial. La fábrica de mampostería está corrientemente enfoscada.

En el interior de la casa, la compartimentación se hace con tabiques de ladrillo o de caña enlucida con yeso, con estructura de delgadas vigas de madera. 
La solería es por lo general de losetas de barro. Se da también un tipo más económico de cal y arena, denominado hormigón. En algunos casos se ponía la losa de barro en la parte habitacional de la casa y el hormigón en la cámara. Tan sólo en los cortijos se usa la solería de tabla.

En lo que respecta a los forjados, las vigas de madera, cuartón, rollizo, viga, viga redonda, listón, se colocaban directamente sobre el muro; sobre ellas se ponían las cañas con la finalidad de servir de soporte a la solería. Las cañas se iban atando paralelas de cinco en cinco, con tomizas. Se consideraba de mayor calidad cuanto más delgadas fuesen las cañas, al resultar así una superficie más lisa. Al espacio que queda entre las vigas del techo (que deja ver la caña) se le llama calle. Se da también otro tipo en el que las vigas descansan sobre las madrinas -soleras-, en una técnica similar a la de la cubierta.

La cubierta habitual es de cuartones, tabicas y cañas, por lo general de dos faldones, aunque sea para cubrir espacios de medianas o pequeñas dimensiones. Es común el empleo de madera de tejo, en viviendas con una cierta antigüedad. Más corrientes son en cambio las de pino, roble o álamo. En las más pobres, las cubiertas estrechas a dos aguas se hacen con pitones (bohordo de la pita).

La armadura, tijera, se montaba apoyando directamente las vigas sobre los muros de carga, aunque a veces se hacía también en rastras: los pares descansaban en las madrinas a las que se les hacía un rebaje de unos 4 ó $5 \mathrm{cms}$. para engarzar los pares. Algunas veces se ponían tirantes o tirantas entre los muros de carga laterales con la finalidad de evitar que se vencieran. La viga cumbrera o hilera se denomina caballete. En las cubiertas se utiliza cañizo y teja morisca - dispuesta en canal y cobertera- fijada con un escarchado de barro.

Como elementos decorativos, es muy frecuente el alero a base de canes y tablazón sobre la que apoyan las tejas; sin embargo, el alero más común es el de pico de gorrión, con mayores o menores complicaciones. Se da también el de bocateja.

En los últimos años se ha hecho corriente pintar con cemento la parte correspondiente al zócalo de la fachada, así como el poyo y la portada.

En cuanto a la construcción de las chimeneas en interior de la casa, se hacían con ladrillo de barro cocido y la forma dependía del gusto del dueño de la vivienda. Se hacían con un partehumos de dos o cuatro huecos en el sombrero. Si por particiones o ventas en cada una de las plantas del inmueble hay una vivienda, la chimenea de la planta baja se saca a ras de la fachada.

Consecuencia de las fuertes pendientes en las que se levantan las casas, es la presencia en algunas fachadas de canales de desagüe de la calle, que pasan bajo la casa.

Las viviendas no tenían vanos muy grandes y en la gran mayoría de los casos se cerraban con rejas de hierro forjado y machihembradas que se instalaban en el marco de la ventana. Las ventanas son de una o dos hojas de madera con contraventanas y en ocasiones con pequeños postigos. La fachada se compone normalmente de dos o tres vanos, el correspondiente a la puerta y la ventana, en la planta baja, y a la ventana de la planta alta; resultan frecuentes los casos de fachadas compuestas por dos grandes vanos en cada planta, correspondientes a dos puertas, accediéndose a la de la planta alta por una escalera de mampostería, integrada a veces en la fábrica de los muros. Los dinteles de los vanos son de rollizos y tablas; de madera son igualmente los cierres, sin postigo ni cristales. Una moldura de listel y pico de gorrión sobre el dintel decora con frecuencia la fachada, decoración que se extiende a veces al alero, voladizo o vuelo, con ese mismo motivo de listel, pico de gorrión y bocateja. Se conservan muy pocos ejemplos de prolongación -con una hilera más de tejas en canal- del alero en el ingreso de la casa. El balcón volado no se corresponde con la vivienda tradicional.

En cuanto a los constructores de las casas, la cuadrilla se componía de un albañil y dos o tres peones, que generalmente eran miembros de la familia que construía la vivienda. De la zona de Vélez-Málaga, en bestias, se traían los ladrillos; las vigas de madera de los árboles que había en los barrancos más cercanos al pueblo; y la cal de las caleras próximas.

En lo que respecta a los tipos de vivienda, podemos decir que la vivienda del pequeño propietario se compone de una o dos crujías, de muy pequeñas dimensiones, compuestas de cocina -la primera crujía- y cuarto, del que arranca la escalera de dos tramos de acceso a la cámara. La fachada tiene tres vanos, dos en la planta baja - puerta y ventana-, y uno en la alta -ventana. La cámara se compartimenta también en dos ámbitos. No tiene patio ni corral.

Contrariamente, la vivienda del mediano propietario es el tipo de vivienda más frecuente, con tres o más plantas, con una o dos crujías. Se dispone sobre una pendiente más o menos pronunciada. A la calle principal, por la que se accede, dan dos plantas, mientras que por la trasera hay tres o más. La planta baja es habitacional, mientras la alta son las cámaras o galerías y en las de abajo se sitúa, el lagar, la bodega o la orujera por último. Suelen tener una puerta de acceso al lagar para dar entrada a la uva (lagareta). Puede tener o no patio trasero. Con el escalonamiento de la vivienda en plantas, la cuadra solía ocupar el bajo o semisótano.

En cualquier caso, las dimensiones de las parcelas son muy reducidas; según la Memoria del Avance de las NN.SS. de Salares el 12\% de las viviendas tiene una superficie útil inferior a $30 \mathrm{~m}^{2}$, el $55 \%$ (acumulado) a $60 \mathrm{~m}^{2}$, siendo en total inferior a $90 \mathrm{~m}^{2}$ el $80 \%$ de las mismas.

La existencia de plantas cuadradas con patio central significa la presencia de tipologías urbanas sin mayor repercusión en la tradición arquitectónica de la comarca.

La casa se distribuye a lo largo del el eje dispuesto entre el corral -o corraleta, a veces con sombrajo-y la calle; por lo general no hay más acceso que la puerta 
de la fachada, cerrada con puerta, portón o con postigo, siendo rara una puerta trasera del corral a la calle, puerta del corral o puerta falsa. El patio, cuando lo hay, es de reducidas dimensiones y da paso a diferentes dependencias de la casa, proporcionando también luz a las habitaciones interiores -en cualquier caso, el interior de la casa resulta muy oscuro cuando se cierran los vanos principales de la fachada. La casa es la dependencia principal, sirve de recibidor, distribuidor y antiguamente también de cocina y comedor, sin más mobiliario que alacena, el chinero, el platero y el rincón -donde se enciende la lumbre-, a partir de la cual se pasa al resto de los cuartos, salas o salillas.

A la cámara -a veces es también arrumbadero, cuarto de los porros o de las pelotas- se sube desde el interior de la casa, y raramente tiene acceso desde el corral; cuando la entrada a ésta se realiza directamente desde la calle se debe a que casa y cámara tienen diferentes propietarios. Los trojes - o atrojes- no son habituales: el grano se solía almacenar en sacos o era vaciado directamente en el suelo de la cámara. La escalera de acceso es por lo general de obra, de uno o dos tramos.

La altura normal en las casas es de dos plantas -baja y alta-, siendo la alta también habitacional, con balcones y grandes ventanas. La presencia de azoteas y terrados no ha sido habitual, según los informantes; sin embargo, en la actualidad se dan casos como el de Alcaucín donde las azoteas, terraos, de factura reciente son ya elemento común llegando a constituir la cuarta planta de la casa.

\section{Montes de Málaga}

La cimentación de la casa es muy poco profunda; en ocasiones, para encontrar el soporte de los cimientos no hay que ahondar demasiado, la mayoría de las veces no más de una cuarta.

Los materiales empleados en la fábrica de las viviendas son los del entorno, esencialmente pobre en materias primas, de modo que el material más importante en la construcción es la tierra, más arcillosa o más silícea dependiendo de los sitios concretos; la piedra es el otro componente importante, en forma normalmente de mampuestos -lastras y laderas- de caliza y esquisto. Una piedra muy utilizada en las poblaciones de Periana y Riogordo es el asperón, que según los albañiles consultados dan buen resultado puesto que es afilada y por esto más fácil de trabar. En otros casos, pocos, se han empleado cantos rodados.

La madera comúnmente empleada es de la zona, principalmente álamo y encina, también se dan especies nuevas, que corresponden con reparaciones recientes de tejados y forjados, como es el eucalipto; la presencia de maderas como el olivo o el chaparro revela una precariedad de medios grande: eran más resistentes pero deformes, con lo que se veían obligados a elegir la cara por la que se iba a utilizar y a calzarlas -si era frecuente emplearlas para los umbrales; en este sentido de marginalidad, se han utilizado incluso pitones, bohordo de las pitas. La presencia del pino, y especialmente el pino rojo, indica un alto status social. En este aspecto hay que decir que se trata de una zona especialmente desforestada desde hace siglos -situación que se repite en el caso de la Ajarquía.

La técnica constructiva principal es pues el tapial, con mortero de barro y más o menos abundante en piedras, si bien en Alfarnate la técnica más frecuente es la mampostería, en muchos casos de piedra seca. Con frecuencia la técnica es mixta, como ocurre en Casabermeja, donde los cimientos y la fábrica de la planta baja son de mampostería, continuando a partir del forjado en tapial, siendo apreciable la huella de los cajones; suelen reforzarse las esquinas con ladrillo. Los muros de tapial tienen como media $70-80 \mathrm{cms}$.; los de mampostería tienen un grosor menor, unos $60 \mathrm{cms}$. Cuando la vivienda tenía varios cuerpos se construían muros de carga intermedios, o bien pilares.

Principalmente, la mampostería constituye la fábrica del primer alzado del muro, de la altura correspondiente a la planta baja. El grosor de los muros es normalmente de 60-80 cms. Se iban poniendo capas de barro de unos $10 \mathrm{cms}$. en las que se trababan las piedras. En la fábrica de mampostería a veces son también visibles las verdugadas de ladrillo.

El empleo del ladrillo es importante; así, en Almogía, muchas casas se levantan sobre bóveda de ladrillo como base de cimentación. Además, se emplea en pilares y esquinas -ya señalado; encontrándose fábricas de muros realizadas completamente en ladrillo.

Otro lugar de empleo de ladrillo es en las portadas de las casas, enlucidas o no, y en el alero, donde como motivo decorativo se disponen ladrillos en listel o en pico de gorrión, las dos formas más ampliamente representadas. En Alfarnate es posible ver también bocateja -excepcionalmente. Se está introduciendo un tipo de alero en el que asoman al exterior las cabezas de las vigas -cuartones muy estrechos. Muy frecuente es también el alero en el que asoman simplemente las tejas soleras sobre la línea de fachada.

La tabicación interior de la casa es de ladrillo o bien de caña y repellado con tierra y yeso.

En cuanto a la solería y pavimentos, el suelo más frecuente es el de loseta de barro, incluyendo una banda de enchinado en el itinerario de la calle al patio. En las casas de propietarios con mayor poder adquisitivo, el ladrillo fue sustituido hace tiempo por mosaico -terrazo decorado. La solería de la cámara es normalmente de yeso pintado de rojo; según los vecinos, antiguamente había también de tablas, pero esto era raro.

Para la cubierta, a dos aguas, se emplea armadura de parhilera.

El montaje de las armaduras se hacía colocando unas vigas -normalmente sin desbastar- sobre los muros, conocidas como zunchos, correas o cargaderos, para ensamblar los pares o vigas que conforman las aguas. En 
algunas armaduras a dos aguas se utilizaban los puentes o tirantes para dar más firmeza a la estructura. Estas vigas se colocaban de muro a muro. Las vigas que se colocan más próximas a los laterales de la vivienda y que en ocasiones se ubican de forma oblicua al conformar un tercer o cuarto faldón se denominan limatones. Si la armadura era a dos aguas se colocaba uno o varios pilares en el medio para sujetar la viga hilera o cumbrera.

Con respecto a los tejados, antes la teja morisca era de una sola forma, tanto la cobija (gambúa o cubía) como la canal (solera), luego, en tiempo que recuerda la informante, la solera se hacía más grande que la gambúa. La fila de tejas que corona el tejado y divide las aguas se denomina caballete.

Los forjados son de cuartones y cañas con yeso, acabados con yeso pintado; los hay también -los menosde tablas sobre vigas. El entramado de los techos se hacía de forma similar a las armaduras: sobre las vigas que descansaban en los zunchos se colocaba la caña como soporte para la solería; las cañas se ataban por manos (de cinco en cinco cañas) con tomizas de esparto, cuerdas que solo sirven para el montaje de las cañas de modo que una vez fraguado el yeso, se pueden cortar-por eso en unas ocasiones se ven, mientras en otras han sido eliminadas. En casas más modernas se han empleado varetas de adelfa (más finas, dando como resultado superficies más lisas).

Para cubrir grandes vanos, se empleaba una estructura de grandes cuartones descansando sobre canes que sobresalen de la pared.

Los techos se dejaban unas veces vistos y sin pintar y otras se pintaban de color amarillo pálido con ocre, destacando o no las vigas respecto del cañizo.

En relación a los cerramientos, todavía se pueden ver vanos cerrados tan solo con madera -ventanas sin vidrios. Cuando la ventana se protege con reja, ésta es de hierro forjado, y va encastrada en el muro.

El acabado de los interiores de las casas es por lo general blanco de cal, pero en muchas otras podemos ver un variado colorido: en algunos casos, la solería de cada cuarto tiene un tono diferente; en otros, son los techos de cada dependencia los que se colorean de forma distinta.

El acabado exterior es enlucido con barro y blanqueado con cal. Los zócalos exteriores a la vivienda se comenzaron a poner hace unos cuarenta años aproximadamente.

En cuanto al equipamiento, el mobiliario tiene una amplia variabilidad en cuanto a la clase social. En las viviendas de clase social baja, se reduce a unas sillas, una mesa y algunas camas, reduciéndose el resto del equipamiento a huecos en la pared, cerradas con puertas -alacenas- o no -vasares, chineros, roperos.

Como ocurría en algunas localidades del Valle del Guadalhorce, Se colocaba una imagen de san Onofre
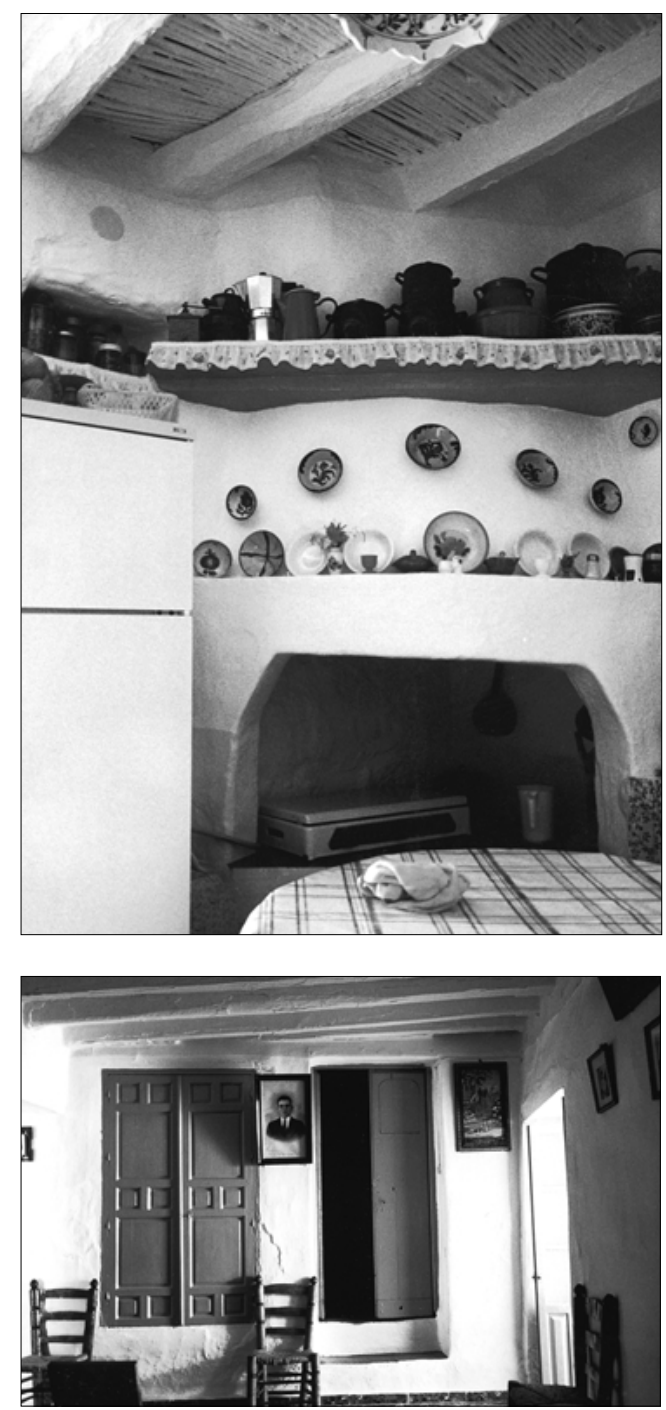

Fotos:

Pilar Ordoñez Vergara

detrás de la puerta de la calle, como "protección"; a veces junto a una herradura, amuleto de la suerte -las buenas eran las de tres agujeros- colgada también de la puerta aunque, según la informante, las herraduras de la suerte son de los antiguos.

Sobre una parcela alargada, adosada a medianería, -de más fondo que anchura, por lo general-, la casa tradicional se distribuye en dos o tres plantas. Esta línea de altura ha sido sensiblemente alterada en los últimos años. La casa se adapta a la pendiente del terreno, elevándose o descendiendo mediante escalones de una crujía a otra.

Podemos establecer dos tipos de vivienda en función del tamaño y especialmente de la especialización de dependencias que se dan en ellas, que son:

- vivienda de una sola crujía,

- vivienda de dos crujías.

En el primer tipo, la vivienda de una sola crujía, el espacio habitacional es mínimo, constando tan sólo de dos habitaciones, separadas por un tabique, correspondiendo el resto del espacio al corral, junto con algunas 
otras dependencias distribuidas en torno al mismo. Esa única crujía se compone de cuarto y cocina -cuarto, sala, sitio de estar, no solo para aviar- situándose la escalera -de un solo tramo- de acceso a la planta alta en paralelo al cuarto, accediéndose a ella desde la cocina. En la planta alta, en ocasiones se compartimenta una de las esquinas para habilitar el espacio como dormitorio, quedando el resto como zona de almacenamiento.

El segundo tipo de vivienda es la que, teniendo como el tipo anterior dos plantas, dispone de dos crujías. Suele estar cruzada por un eje transversal a las dos crujías en la planta baja, marcado por la puerta principal de la vivienda y la puerta del patio, cruzando un muro de carga por medio de un vano. Generalmente este pasillo estaba empedrado en origen para el paso de las bestias. Suelen tener un patio trasero donde se ubican la corraleta (o marranera), la cuadra y en la actualidad suelen tener también un aseo y/o una cocina anejos a la vivienda, como resultado de las nuevas necesidades.

La fachada, en cualquiera de los dos casos, consta normalmente de dos o tres vanos en cada planta, siendo en la planta baja una puerta y una o dos ventanas, y en la alta de una a tres ventanas, dependiendo de la clase social del inquilino. La organización de la fachada se basa en una puerta de acceso central, con dos vanos de pequeño tamaño en la planta baja, a derecha e izquierda, con reja encajada en el marco, y uno o dos vanos en la planta alta del mismo tipo que los anteriores.

Las diferentes dependencias se distribuyen esencialmente en la planta baja. La principal es el cuerpo de casa, la casa, habitación multifuncional a la que da el acceso principal a la vivienda, que hace las veces de recibidor-sala de estar-comedor, y antiguamente también cocina. En ella se ubica la chimenea de campana, elemento esencial en la casa, que ocupa uno de los testeros, situándose a los lados, en los huecos de la campana, dos alacenas o chineros. Desde la casa se puede acceder al (o a los) cuarto(s), a la cuadra -espacio que se ha adaptado luego para cocina-, y al patinillo y corral, en el fondo de la parcela. Del cuerpo de casa arranca también la escalera de acceso a la planta alta, en la que se sitúan uno o dos cuartos, ahora adaptados a dormitorio, si bien antiguamente tenían función también de granero o almacén. En las casas de tres plantas, en las que la planta baja suele tener función comercial o profesional, la última se destina a ese fin.

El espacio habitado, doméstico, es -y era aún más- inferior al espacio total disponible, de producción económica. Los patios y corrales ocupan la mayor parte de la superficie. La casa traza también el eje entre el corral y la calle; por lo general no hay más acceso que la puerta de la fachada, siendo rara una puerta del corral a la calle, una puerta trasera. Igualmente, a la cámara se sube desde la casa, salvo en un caso en el que el acceso se realiza desde el corral. La escalera es de uno o dos tramos.

Respecto a la confortabilidad de las casas, un comentario habitual es que ahora hace más frío en las casas que antes: mientras antiguamente se encendía la candela en el humero al empezar el día, ahora, salvo en reuniones familiares o en fiestas "señaladas", no se enciende la chimenea porque se ensucia mucho la casa; así, el único elemento de calefacción es el brasero de la mesa camilla.

Una de las modernizaciones son las cancelas con vidrios en las puertas de entrada a las casas, de modo que se permite un poco más de luz en el interior. Pero quizá la más común es la reforma de las solerías, sustituyendo la de ladrillo o las laderas por terrazo.

\section{A modo de conclusión,}

con lo visto en esas localidades y comarcas, podemos decir que se trata de una arquitectura de época moderna y -principalmente- contemporánea, de marcada funcionalidad, adecuada al terreno; susceptible, por su adaptabilidad a los usos y necesidades actuales, de seguir siendo útil para quienes las habitan, así como de rendir beneficios a la comunidad a través del mantenimiento de los conjuntos urbanos y del paisaje, y de la repercusión de éstos en términos de desarrollo socioeconómico y cultural.

Notas

I. Contratada en las dos primeras fases en la modalidad de "específico" y en la tercera de "consultoría", por la Dirección General de Bienes Culturales.

2. Eugenio Cifuentes y Jaime López colaboraron en la realización del trabajo en algunas localidades de la Ajarquía y de los Montes de Málaga.

3. Dos maneras de ver la cuestión que, si bien no son contradictorias, su simultaneidad resulta problemática al exigir una intensidad de trabajo -dada por la información requerida en la ficha de campo y la extensión territorial- que sobrepasaba el marco temporal y presupuestario dado, a la vez que resta seguridad en la realización por la inconcreción de límites.

4. Salvo que se trate de lugares que cuenten con alguna figura de protección.

5. Y en las que el trabajo resulta especialmente difícil y penoso si no se es hábil en el manejo de técnicas de trabajo social.

6. Especialmente frecuente en Cañete la Real.
7. FEDUCHI, L. Itinerarios de arquitectura popular. vol. IV (Provincia de Málaga). p. 178

8. Pudiera ser que también se guardara en la casa una imagen de San Pascual Bailón, pero no se ha conservado en ninguna de las casas vistas.

9. Onofre el Grande. Santo asceta. Festividad: 12 de junio. Vivió en el siglo IV y principios del $\mathrm{V}$; después de educarse en el monasterio de Hermópolis, habitó sesenta años como eremita en Tebas. JÖCKLE, C. (1995): Enclyclopedie of saints. Londres. p. 345-346.

10. Biblioteca Santorum. Florencia.

I I. Observación del profesor Sotomayor, S.J.

12. Avance de las Normas Subsidiarias de Salares. Diputación Provincial de Málaga. 